\title{
Sessile serrated lesion misdiagnosed as a hyperplastic polyp
}

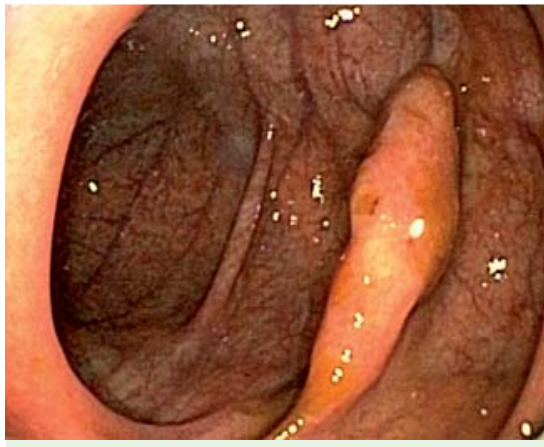

Fig. 1 Endoscopic appearance of a prominent fold identified in the proximal ascending colon during a colonoscopy performed 5 years prior to presentation.

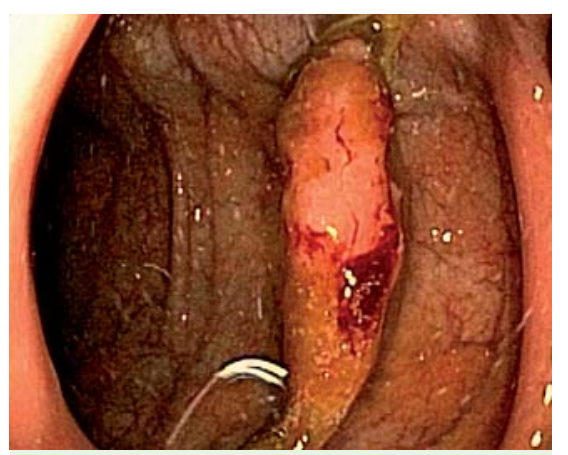

Fig. 3 Endoscopic appearance of the polyp in the proximal ascending colon during a colonoscopy performed 1 year later, showing no significant change.

An 81-year-old woman presented for colonoscopy because of iron deficiency anemia. She had undergone colonoscopy 5 years previously during which a $2-\mathrm{cm}$ prominent fold had been identified in the proximal ascending colon ( $\bullet$ Fig. $\mathbf{1}$ ). A biopsy of this lesion was interpreted as being a hyperplastic polyp ( $\bullet$ Fig. 2 ), although the polyp showed features of a serrated lesion. Because of clinical concern over a more sinister process, colonoscopy was repeated 1 year later. The endoscopic appearance of the area of concern was unchanged ( $\mathbf{F i g . 3}$ ); biopsies were again interpreted as being consistent with a hyperplastic polyp. Endoscopic resection was not performed.

At the time of re-presentation, she was found to have a hemoglobin of $6.1 \mathrm{~g} / \mathrm{dL}$. Colonoscopy was repeated and she was found to have a $5-\mathrm{cm}$ nongranular, cen-

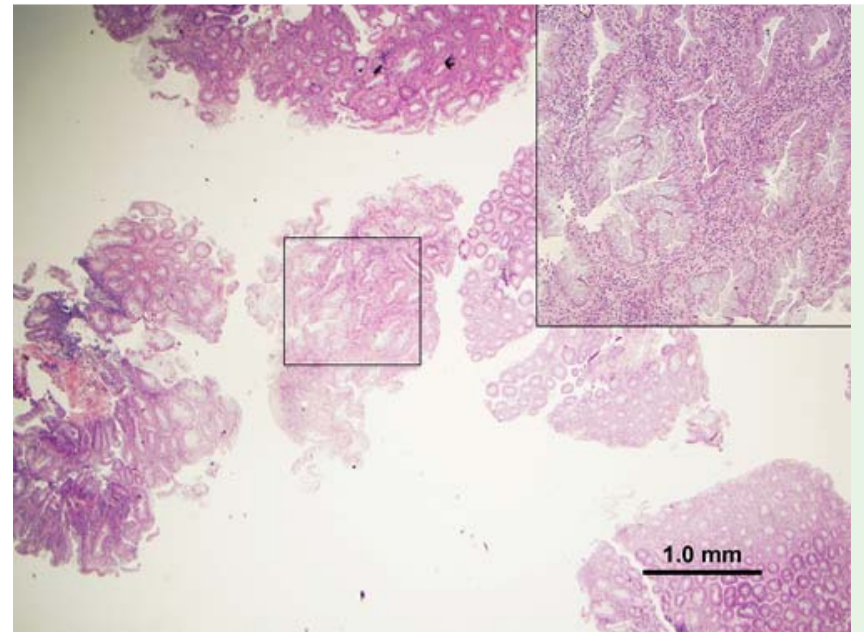

Fig. 2 Biopsy of the lesion found 5 years previously, which was initially interpreted as being a hyperplastic polyp, although on later review features of a serrated polyp were identified.

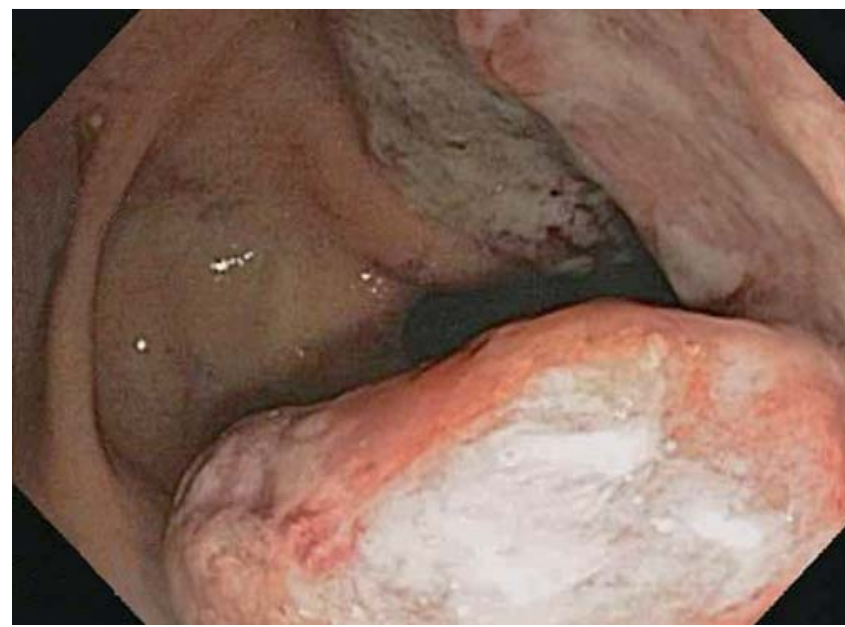

Fig. 4 Endoscopic appearance during a colonoscopy performed for investigation of anemia showing an invasive colon cancer in the area where the "hyperplastic" polyp had initially been seen 5 years previously.

trally depressed lesion that was suspicious of malignancy in the same location within the proximal ascending colon ( Fig.4). Endoscopic biopsies of this lesion were consistent with invasive adenocarcinoma. She underwent laparoscopy-assisted right hemicolectomy and partial hepatectomy of two metastatic lesions; a third lesion was ablated by interventional radiology. Final pathology revealed a $6.9-\mathrm{cm}$ mass with two metastatic liver lesions, stage T3NOM1a. Review of the initial biopsies confirmed that the proximal ascending colon polyp seen initially 5 years previously was a sessile serrated lesion.

Although in the past many serrated lesions were misdiagnosed as benign hyperplastic polyps, increasing pathologist and endoscopist recognition has reduced the rate of occurrence of this error [1]. Serrated le- sions are now recognized as an important neoplastic precursor to adenocarcinoma of the colon [2,3]. After reinterpretation, many lesions identified as hyperplastic in the past can be reclassified as serrated lesions [4]. In the illustrated case, the initial biopsies had features suggestive of a serrated polyp but were misinterpreted as hyperplastic because of the reduced recognition of these lesions at that time and the limitations of interpreting polyp pathology from small forceps biopsies. As endoscopic mucosal resection of large polyps is a safe and efficacious technique, polyps should be resected to ensure accurate pathology. The illustrated case is unique as it demonstrates the unfortunate natural history of an unresected serrated adenoma, developing into a metastatic adenocarcinoma over a 4 -year time period. Furthermore, the case highlights the limita- 
tions of optical and histologic diagnosis of serrated polyps and the critical importance of resecting these lesions because of their malignant potential.

Endoscopy_UCTN_Code_CPL_1AJ_2AB

Competing interests: None

\section{Rajesh N. Keswani ${ }^{1}$, A. Aziz Aadam',} Guang-Yu Yang ${ }^{2}$

${ }^{1}$ Division of Gastroenterology, Department of Medicine, Northwestern University Feinberg School of Medicine, Chicago, Illinois, USA

2 Department of Pathology, Northwestern University Feinberg School of Medicine, Chicago, Illinois, USA

\section{References}

1 Singh H, Bay D, Ip $S$ et al. Pathological reassessment of hyperplastic colon polyps in a city-wide pathology practice: implications for polyp surveillance recommendations. Gastrointest Endosc 2012; 76: 1003 - 1008

2 Bouwens MW, Riedl RG, Bosman FT et al. Large proximal serrated polyps: natural history and colorectal cancer risk in a retrospective series. J Clin Gastroenterol 2013; 47: $734-735$

3 Sweetser S, Smyrk TC, Sinicrope FA. Serrated colon polyps as precursors to colorectal cancer. Clin Gastroenterol Hepatol 2013; 11: $760-767$

4 Khalid $O$, Radaideh S, Cummings $O W$ et al. Reinterpretation of histology of proximal colon polyps called hyperplastic in 2001. World J Gastroenterol 2009; 15: 3767 - 3770

\section{Bibliography}

DOI http://dx.doi.org/ 10.1055/s-0033-1358928 Endoscopy 2014; 46: E7-E8 (c) Georg Thieme Verlag KG Stuttgart · New York ISSN 0013-726X

\section{Corresponding author} Rajesh N. Keswani, MD

676 N. St. Clair, Suite 1400

Chicago

Illinois 60611

USA

Fax: +1-312-695-6999

raj-keswani@northwestern.edu 